\title{
A Case of Leucocoria Caused by Visceral Larva Migrans
}

\author{
Major R K Goel, \\ RAMC \\ Senior Specialist in Opthalmology, QEMH, Woolwich
}

SUMMARY: A four-year-old boy was seen in the Eye Department at the Queen Elizabeth Military Hospital, Woolwich, because his parents had noticed that his right pupil appeared white. The diagnosis of toxocaral endophthalmitis was laterc made. The pathogenesis and management of infestation by Toxocara species are described.

\section{Case Report}

The four-year-old son of an Army Warrant Officer was referred by his family doctor to the Eye Department at QEMH Woolwich because it had been noticed that his right pupil appeared whitc. The child had complained only of occasional discomfort in bright light. His general health was reported to be excellent and there was no family history of ocular disease. He had been born at full term by spontaneous delivery and had lived in Germany for two years where his father was serving. The only point of possible significance in the history was that the family had acquired an eightweek-old cocker spaniel puppy about three months before the child had been taken to the GP.

\section{Ocular Findings}

The child's left eye was normal. On the right, the palpebral aperture was found to be slightly narrower than on the left and there was minimal congestion of the conjunctiva. The cornea was clear and the anterior chamber was quiet (Fig. 1). There were adhesions between the iris and the lens (posterior synechiae) but the lens was clear. There was a white mass behind the lens, on which superficial blood vessels could be seen (Fig. 2). Digital tonometry revealed that the eye was very soft and it was inferred that the narrowed palpebral aperture was due to reduction in the size of the globe from shrinkage.

General physical examination did not reveal any abnormality.

\section{Differential Diagnosis}

When a child presents with leucocoria (white pupil) one is faced with an urgent problem in differential diagnosis. The chief possibilities are:-

1. Cataract.

2. Retinoblastoma.

3. Retinopathy of prematurity with retrolental fibroplasia.

4. Coat's disease (retinal exudative disease often with malformation of blood vessels).

5. Persistant hyperplastic primary vitreous.

6. Massive retinal detachment.

7. Toxocariasis.

\section{Investigation}

The investigations in this case included full blood $\vec{\omega}$ count, chest and skull X-ray, B-scan ultrasonic examination of the eye and the enzyme-linked@ immunosorbent serum assay test (ELISA) with? Toxocara antigen.

The blood picture was normal except for a relative eosinophilia of $9 \%$ on the differential count. The chest and skull X-rays were reported as normal. B-scan $\stackrel{1}{-}$ ultrasound showed a rigid, funnel-shaped total retinal detachment with the leaves of the retina in apposition at the nerve head (Fig. 3). This confirmed the clinicol impression, formed on slit-lamp examination, that t $\overrightarrow{8 c}$ white body seen behind the lens was detached retine The ultrasound result was thought sufficiently specific fo exclude tumour. The ELISA test was strongly positike $\vec{\bullet}$ for anti-toxocara antibodies.

\section{Diagnosis}

On the basis of the history, the clinical findings, th strongly positive ELISA test, the eosinophilia and theo ultrasound exclusion of intra-ocular tumour, a diagnosis of toxocaral endophthalmitis with secondary retinal detachment was made. Unfortunately, the eye wasoㅡㅡㅁ irreparably damaged, and later enucleation, or the fitting of a full-size prosthetic shell, may prove necessary? to prevent orbital mal-development and facial asymmetry.

\section{Discussion}

Ocular toxocariasis, as a manifestation of visceralä larva migrans (VLM), is a fascinating clinical entity and $\stackrel{\frac{0}{7}}{\frac{7}{7}}$ is now recognised as an important cause of visual loss in:children. It has been estimated that about 100 eyes are 3 . affected by this cause in the United Kingdom each year. The condition is commonly confused with retinoblas-3 toma and many eyes have, in the past, been unnecessa-o rily enucleated because of this ${ }^{1}$. Retinoblastoma is, of course, of such high malignancy that surgeons have felto compelled, when in doubt, to err on the side of caution. As a result, a number of reviews of series of eyes enucleated for presumptive retinoblastoma have shown 0 that toxocariasis was the true diagnosis in a significant proportion of cases ${ }^{2}$. 
Improved diagnostic methods available today, especially ultrasound, CT-scan, nuclear magnetic resonance and the ELISA test enable the diagnosis to be made much more often.

Ocular infestation with Toxocara juveniles is essentially a condition of young children and is usually unilateral. It has, however, been reported on both sides, and when it occurs in adults the ocular appearances are very variable and none is pathognomonic, so all available aids to diagnosis must be employed. The commonest ocular manifestation is choroido-retinitis with a white mass at the posterior pole. Alternatively, but infrequently, there may be a peripheral choroidoretinitis, an optic neuritis or an endophthalmitis. Occasionally a living juvenile worm may be seen moving beneath or across the retina. Rarely, there is keratitis or conjunctivitis.

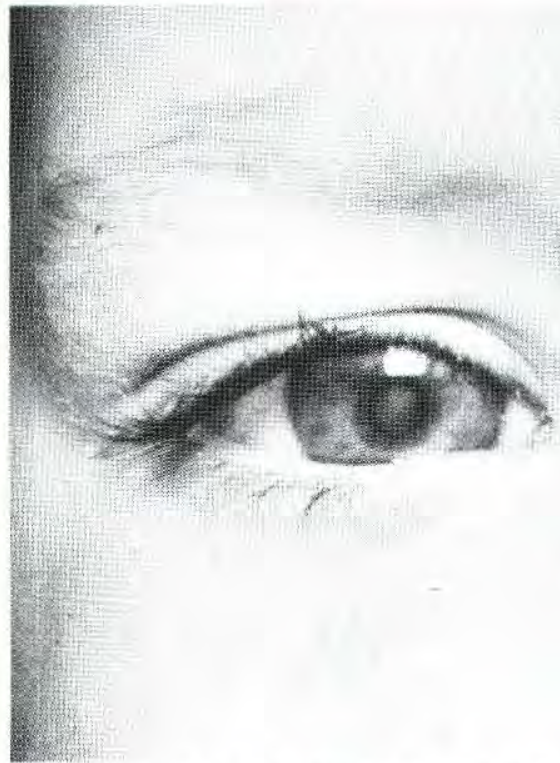

wall into the blood-stream. They are then carried throughout the body until they reach a blood vessel with a diameter smaller than their own, and at that point they burrow into the tissues. In the lung they leave the blood vessels and enter the bronchioles, migrate up the trachea, assisted by ciliary action and coughing, and are swallowed. They may then mature into adult worms in the intestine and the females lay ova which are passed in the faeces and which contaminate the peri-anal fur.

Life Cycle in the Human. Infestation is normally by ingestion of ova and this is why the condition is so common in children, who are more likely to come into contact with puppy fur and contaminated soil. London parkland has been shown ${ }^{3}$ to be extensively and

Fig. 1. Appearance at presentation. Note the narrow lid aperture, small pupil and opaque optical medium.

\section{Parasitology}

Toxocara canis is a nematode intestinal round worm of dogs. A closely related species Toxocara cati, occurs in cats. In its natural host, the dog, the life cycle parallels that of Ascaris lumbricoides in man. The dog may acquire the parasite in several ways - by ingestion of ova in contaminated soil, etc., by trans-placental migration, by way of milk from the lactating mother or by ingestion of the late stage juveniles or immature adult worms in the vomit or faeces of other infested puppies. (Note that the term 'larvae' is incorrect in a species whose juveniles are morphologically identical to the adult forms. A larva is, by definition, different from the adult).

Life Cycle in the Dog. The ova hatch in the small intestine and the juveniles pass through the intestinal uniformly contaminated with Toxocara ova. When the eggs are ingested they hatch in the small bowel and the juveniles penetrate the mucosa to gain access to the portal circulation and the lungs. In this case, however, they are able to pass through the lungs to reach the systemic circulation and proceed to any organ in the body. Contrary to events in the dog, the juveniles do not return to the lumen of the human bowel, so the life cycle is incomplete. Thus ova are not found in the human stools and examination of these is not helpful. Juveniles can remain viable in the tissues for many weeks and tend to produce tracks of haemorrhage, necrosis and inflammatory cells. At the sites of death of the parasites, typical eosinophilic granulomas or abscesses occur. Live juveniles may remain walled up for years only to resume their migration at a later date. 


\section{Clinical Features}

VLM occurs most frequently in males between the ages of six months and three years. There is usually a history of close contact with puppies and of geophagia or pica. The clinical signs are not very specific and are those of a transient illness with fever, pallor, lassitude, anorexia, loss of weight and often cough and wheezing bronchospasm. Rarely, epileptiform attacks - usually of the petit mal type-occur. Poliomyelitis and myocarditis have been described.

Human infestation is probably commoner than has been supposed for many cases are asymptomatic. Serological surveys have shown that in some groups of children (black youngsters in the Southern States of the USA) up to $25 \%$ have antibodies to Toxocara. White children in the same ares show a prevalence of about $5 \%{ }^{4}$. Symptomatic cases are determined by the number of live ova ingested and by the resistance of the host. Eye involvement is uncommon, possibly because of the angle made between the ophthalmic artery and the internal carotid. It is clear that only a small minority of those infested suffer ocular affects.

\section{Serological testing}

In the past there has been no reliable test specific for toxocara and the major problem was cross-reactivit黑 between $T$. canis and other ascarids, especially $A \odot$ lumbricoides. A child who had had early or minimig ascaris infestation might not show ova in the stools biẹp would react positively to skin testing and the fluorescer antibody test. The ELISA test, using $T$. canis antigen, a significant advance and has a sensitivity of about $80 \%$ and a specificity of about $90 \% 5,6$. This increase reliability, taken in combination with other clinical an laboratory findings, now enables us to make the dia® nosis with considerably more confidence and, hopछे fully, to avoid, more often than in the past, the tragedy of unnecessary enucleation of the eye $\mathrm{e}^{7,8}$.

\section{Treatment}

This is a difficult problem, and if severe damage ha been done to the eye at the time of presentation, litter benefit may result. Topical or systemic steroids may bॄ্ট used to try to minimise the inflammatory reaction and these may be combined with diethylcarbamazine or thię

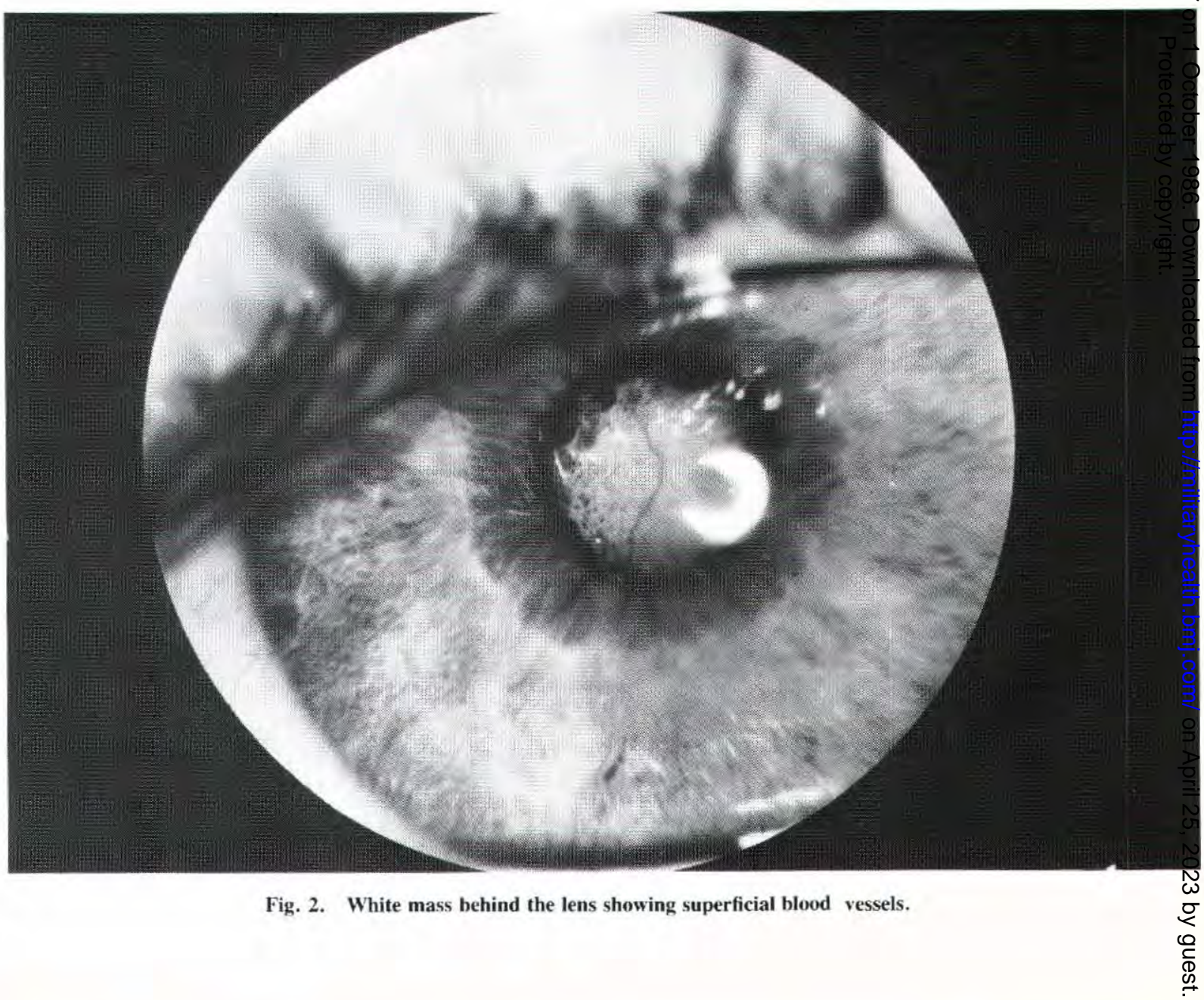




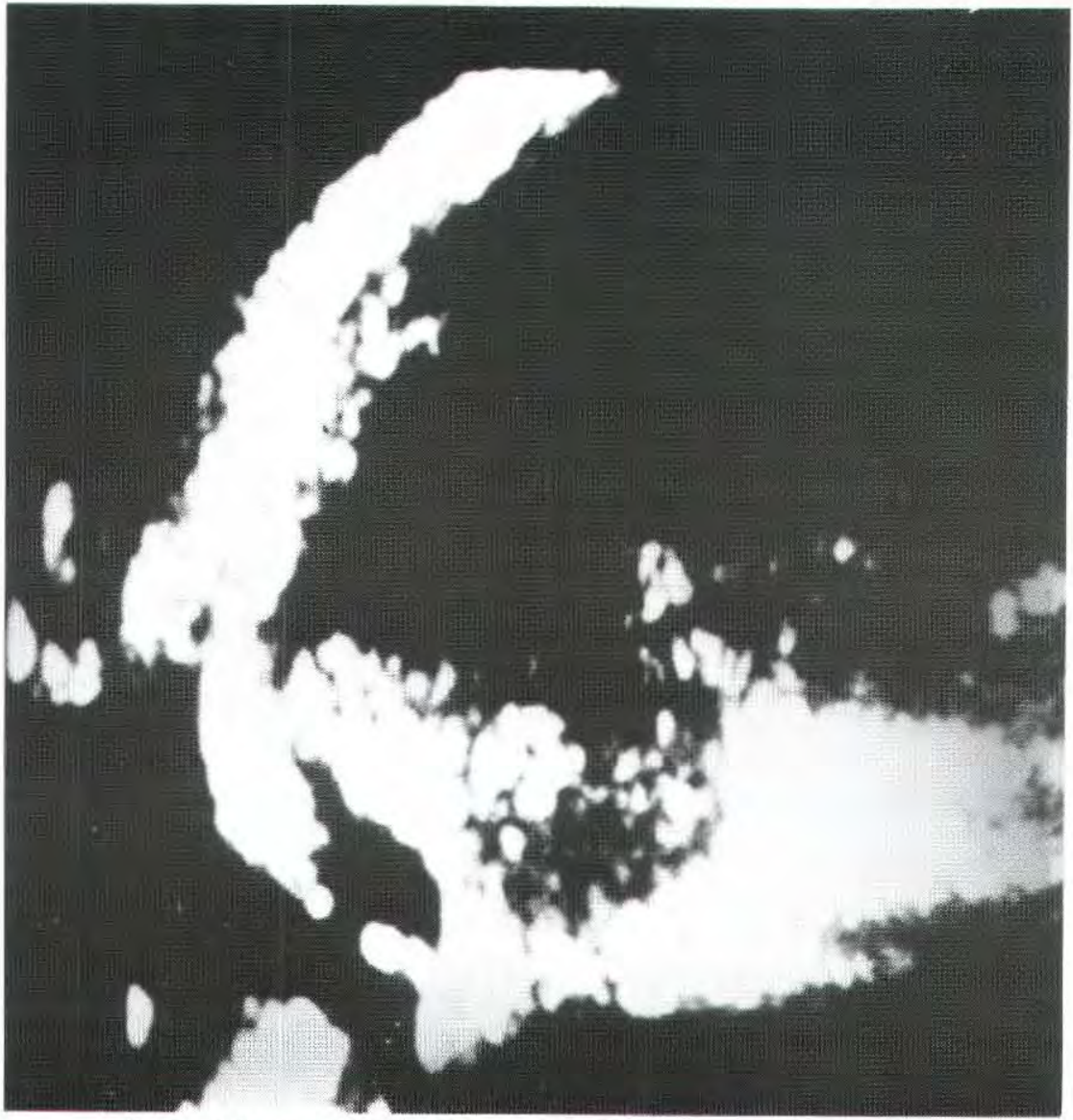

Fig 3. Ultrasound (B-scan) showing funnel detachment of the retina.

bendazole. Photocoagulation has been used to kill the juvenile worm and to prevent its migration to the macular area of the retina.

Prevention is, of course, better than cure. Many puppies are infested in utero and require de-worming with piperazine adipate, at two, three, four and eight weeks after birth and then twice more between three and six months. Thereafter, one further dose is desirable. Pregnant bitches should also be repeatedly treated with the same anthelmintic. All dog faeces should be collected and destroyed as the ova can survive for years in soil. It has been proposed that special dog exercise areas should be set aside in parks, from which children would be excluded and both parents and children should be educatd in the dangers associated with puppies. Pica should be discouraged.

\section{Acknowledgement}

I am grateful to Colonel R M Youngson, Consultant Adviser in Ophthalmology, for his advice and assistance in the management of this case and in the preparation of this paper.

\section{REFERENCES}

1. Browv D H, Ocular Toxocara canis. I Pediatric Ophthalmol 1970; 7: 182-191

2. Ashton N. Larval Granulomatosis of the Retina due to Toxocara. BrJ Ophthalmol 1960; 44: 129-148.

3. Borg O A and Woonruff A W. Prevalence of Infective Ova of Toxocara Species in Public Places. Br Med J 1973; 4: 470-472

4. Glockman L T and Schantz P M. Epidemiology and Pathogenis of Zoonotic Toxocariasis. Epidemiol Rev 1981;3: 230.

5. Pollard $Z \mathrm{~F}$, Jarrett $\mathrm{W} \mathrm{H}$ and Hagler $\mathrm{W} \mathrm{S}$ et $\mathrm{al}$. ELISA for Diagnosis of Ocular Toxocariasis. Ophthalmology 1979; 86: 743-749.

6. Shields J A, Feldberg N T and Federman J F. Discussion of ELISA for Diagnosis of Ocular Toxocariasis. Ophthalmology. 1979; 86: 750-752.

7. Shields J A. Ocular Toxocariasis. A Review. Surv Ophthalmol 1984; 28 (5): 361-381.

8. Motk R. Ocular Toxocariasis. A Review of the Literature. Ann Ophthalmol 1983; 15: (3): 216-231. 